\title{
See One, Do One Teach One
}

To the Editor:

Recently I had the opportunity to speak at grand rounds at the institution where I performed my residency. I was thrilled to be able to return to talk with the people that gave me a chance to enter the field of my desire and give back to the present residents. My talk utilized the previous medical standard, dual slides. Although I was a bit under the weather, I tried to be as entertaining as possible, moving around not staying behind the lectern, and speaking to the audience. The residents seemed underwhelmed, however, the physical and occupational therapists along with the attending physicians asked excellent questions engaging me in a educational post-presentation discussion. My perception that the residents were not invested was underscored by their lack of participation as neither a question nor a comment was offered by them.

I'm now preparing a talk for an internal medicine board review course and have been informed that my slide show is no longer acceptable; I must join the new millennium and convert to cd-rom disc. I discussed this with the leadership, as I am out of town (event coverage), alternative methods of presentations that would be dynamic in nature, including utilizing a white board. Alas, only a disc formatted presentation is acceptable. Fortunately for me the original disc from which I made my original slides was found, converted and is now ready to go. I've bought a digital camera and have been obtaining images daily. But, my initial thoughts of what makes a good, memorable presentation that other physicians can do more than spend an hour or so of their time just for a pearl or two, or even worse a "take home message"?

My third year of medical school started out much like everyone else's, with internal medicine. My resident showed me how to obtain an EKG with the old style single lead machine, and then I was sent to do one on my own, then to show another medical student. Even though it's been some time, I think I can still obtain one appropriately. I am not sure many of the lectures that I have attended, regardless of how well presented, have been committed to memory. "Take home messages" do resound in my mind, but is this the best or even a reasonable approach to medical education? Especially as I have been reminded, the amount of tuition that attendees are asked to pay for a conference or lecture.

In 1998, Freedman and Bernstein (1) looked at the amount of musculoskeletal training and knowledge that interns had as they entered their training program at a large university hospital. They noted that these highly prized physicians, many of whom graduated at the top of their medical school classes had only a limited exposure to formal musculoskeletal training (2.1 weeks, $33 \%$ no exposure at all) and limited knowledge of seemingly basic conditions and treatments. Moreover, it didn't seem likely that those in primary care fields would get much more training. Two follow-up studies by the same group asked program directors of both orthopaedic surgery $(n=124)$ and internal medicine programs (240 out of 417) to not only give this test to incoming residents but, also asked questions to the directors with regards to fairness of question and what would be appropriate passing scores by percentage. Both director groups chose rates of about seventy percent and in fact 78 percent of new interns flunked by a wide margin (mean score 59.2\%). Thus, the authors have concluded that more musculoskeletal instruction is needed at the medical school level $(2,3)$.

Many of us are involved with student, resident and or fellow education. Anecdotally, it can be agreed upon that there is no substitute for experience. Those of us who work on, subscribe to, or casually read this journal could agree that we're better clinicians now than five or ten years ago. We, the current generation of clinicians have a wide array of technology available to help diagnose and treat our patients, which only a generation ago seemed like fantasy. How will this technology boom take medical education to a higher level? What will it substitute for? And will technology allow a mundane topic or speaker to become more dynamic by a more interactive ebb and flow of information?
There's been more than one didactic session that despite the speakers eloquence and true zeal for the subject matter that I have either tuned out to or forgotten over time, most likely since I have no current use for subject matter in a daily basis. But, for all the lectures that I did find an enjoyable learning experience, I recall hours of independent study that many of my classmates foresaw by not attending the lecture altogether.

Our residencies and fellowships serve as apprenticeships from which, we hope modern masters of medicine will be forged. Although I read more during my fellowship than at anytime since second year of medical school, the application of that knowledge on a daily basis is what led to retention of that knowledge. How then do we continue the traditions of medicine in the twenty-first century? I do not know the answer, but now is the time that we all should come together to help educate the next generation. You don't need any fancy, state of the art electronics, just your mind and your heart in the right place.

Sometimes, just letting another attending physician, resident, student, or therapist experience what you do on a daily basis can help the field tremendously. The time spent with you will do more than any lecture could. We need to instill in our newer colleagues not only the thought of becoming an interventionalist, but to allow those that do not desire such a practice the opportunity not only to see but to also understand the true benefits of your practice.

\section{REFERENCES}

1. Freedman KB and Bernstein J. The adequacy of medical school education in musculoskeletal medicine. J Bone Joint Surg Am 1998; 80:1421-1427.

2. Freedman KB and Bernstein J. Educational deficiencies in musculoskeletal medicine. J Bone Joint Surg Am 2002; 84:604-609.

3. Dicaprio MR, Covey A, Bernstein J. Curriculum requirements for musculoskeletal medicine in American medical schools. J Bone Joint Surg Am 2003; 85:565-567.

\section{Mark I. Ellen, MD}

Emory Health Care

The Emory Clinic, Inc

1365 Clifton Road, NE

Atlanta, GA 30322 